\title{
Ethics, Technology and Organizational Innovation
}

\author{
Stefano Brusoni ${ }^{1} \cdot$ Antonino Vaccaro $^{2}$
}

Received: 13 May 2015/Accepted: 28 January 2016/Published online: 23 February 2016

(C) Springer Science+Business Media Dordrecht 2016

This symposium offers a discussion about the impact of ethics-related variables on the development of new products, services and on organizational innovation. It proposes a multi-disciplinary perspective that links several strands of research including: political CSR (Scherer and Palazzo 2007, 2011), social entrepreneurship (Santos 2012), hybrid organizations (Battilana and Lee 2014), innovation and adoption issues in sustainability (Berrone et al. 2013), corporate transparency (Vaccaro and Madsen 2009; Vaccaro 2012), etc.

The idea of the guest editors is to highlight and discuss the increasing importance, and visibility, of ethics in decision-making processes associated with product, service and organizational innovation. We believe that the relevance of ethics for the analysis of innovation is rooted in strong empirical evidence about the increasing expectations and attention of consumers, and more in general of the civil society, about these issues. Yet, the topic still fails to attract the attention of scholars and researchers, particularly in the innovation studies community. This gap has important implications for both research and practice.

For example, digital companies publicly recognize the importance of users' privacy. Yet, they still struggle to adapt their new product and service development processes to include these considerations when the technology is still malleable and open to be modified in ways that are less likely to generate problems down the line. Facebook's privacy scandal saga (Tatton-Brown 2012) is one among many well-known global examples of these tensions.

Stefano Brusoni

sbrusoni@ethz.ch

ETH Zurich, Rämistrasse 101, 8092 Zurich, Switzerland

2 IESE Business School, Avenida Pearson 21, 08017 Barcelona, Spain
Similarly, it is a very rare event to find in the readings and technical notes of top-ranked MBA courses a discussion about how to introduce ethics in product, service and organizational innovation. Yet, several studies show that important ethical issues such as security, reliability and transparency ought to be given center stage in the discussion about how designers of new products and services can and should frame their activities, in important sectors such as automotive (see, e.g. Thomke 2003).

Thus, it seems that, both the managerial literature and practice still fail to fully recognize the importance and the great opportunities associated with ethics in product, service and organizational innovation. What this collection of papers intends to foster is a discussion about how ethics could become an integral component of the discourse about technological and organizational innovation, rather than remaining an after-thought to be discussed only when and if problems occur.

Indeed, individuals and organizations differ in how they deal with ethical issues and this difference position them within the market as well as civil society. The ethical standing of an organization-that is represented by its internal practices, products and services-clearly provides a unique way to differentiate from competitors.

We should never forget that the very same technology, ${ }^{1}$ that is by definition ethically neutral (Kaplan 2004, pp. 227), can be developed and used in dramatically different ways. There are organizations that currently exploits internet-based technologies to manage 'digital sweatshops', i.e. overcrowded rooms where workers play online games for up to twelve hours a day in order to create virtual goods, such as characters, equipment's or in-game

\footnotetext{
${ }^{1}$ Here we use the term technology referring to a product, service or to an organizational activity/procedure.
} 
currency, which can then be sold to other, obviously richer, players (Floridi 2009, p. 14). But, there are other kinds of organizations, such as Samasource, that use the very same technology to empower women, increase the freedom of disadvantaged people in very poor and underdeveloped areas of the world supporting human integral development (Gino and Staats 2012).

Thus, the very same technology, used in very similar organizational conditions (e.g. distant, virtual work), can provide very different internal and external outcomes depending on how and when in the innovation process ethics-related variables are taken into account.

These considerations highlight the need to further our understanding of the role played by ethics-related variables in new product and service development and more in general in firms' innovation efforts (see, e.g. Adolphson 2004; Madsen 2005).

Our standpoint is value-based. We acknowledge the importance of cultural variation but we assume the existence of intrinsic fundamental values (see, e.g. the UN Declaration of Human rights) that represent a base for the solution of any kind of problem. We believe that this assumption is extremely important in discussing these issues because of their multi-cultural and complex nature.

Indeed, given the intrinsic ethical neutrality of technologies per se, values play a central role in this discussion. Individual and organizational values shape how technologies (product, services, procedures) are understood and practiced. In addition, this has a dramatic impact on internal and external outcomes (please, see Fig. 1).

A technology that is used in a way that addresses some pro-social ethical values, such safety or respect of human dignity, affects positively the organization life and culture because it reinforces the importance of those values through their continuous operationalization in day-to-day life activities. Thus, technologies can be used to support virtuous behavior within organizations.

But, the use of a technology driven by values can also have positive outcomes outside the organization. This is the case of a technology that influences the external environment and/or external stakeholders. For example, environmental technologies adopted within production facilities have a positive impact on the external environment by reducing the levels of pollution but also show to the local population the importance of environmental preservation.

Thus, technologies can be a unique way to embed, spread and convey ethical values. We believe that this is a different perspective about corporate social responsibility that should be taken in more consideration by scholars and practitioners.

This Symposium is composed by six different papers.

The first paper, by Christian Voegtlin and Andreas Georg Scherer, explores innovation as a way to resolve sustainability mega-problems adopting a political CSR perspective (Scherer and Palazzo, 2007, 2011). More specifically, the paper discusses global governance approaches based on deliberation as a strategy to support responsible innovation. According to the authors such kind of solutions can provide the necessary, voluntary soft-law regulations that complement traditional law-based solutions and in turn facilitate collective and responsible innovation.

The second paper [Safety Reloaded: Lean Operations and High Involvement Practices for Sustainable Workplaces, by Camuffo, De Stefano and Paolino.] proposes an interesting perspective of occupational safety as an important aspect of corporate responsibility and sustainability. More specifically, it focuses on a specific case of organizational innovation, namely the adoption of lean operations, high involvement work practices and management behavior and their impact on occupational safety. Relying on a unique database, i.e. the activities of 32 production departments from 9 plants in 7 countries of one of the world's largest tire manufacturer, it shows that high involvement work practices and two specific management behaviors, i.e. workers' capability development and empowerment, positively affect occupational safety. The results also point out that empowering behaviors positively
Fig. 1 From technologies to outcomes through value-based uses

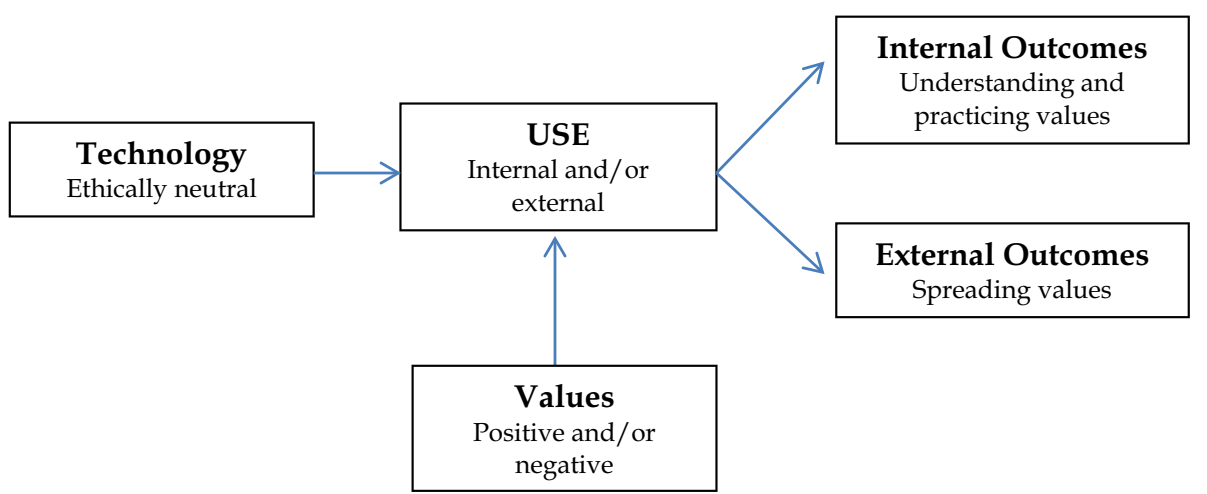


moderate the effect of lean operations on workers' safety. We believe this paper well captures the spirit of this Symposium, as it shows how lean practices (developed quite independently of any discussion about ethics) can instead be enriched by the discussion about ethics to deliver results that go beyond the original scope of that discussion.

The third paper [Threat Interpretation and Innovation in the Context of Climate Change: An Ethical Perspective, by Aoife Brophy Haney)] provides a very detailed, microlevel analysis of how ethical considerations may affect the ability of firms to react to environmental challenges. Managers' responses are affected by their framing of a situation. Environmental clues can be read as either threats or opportunities. The former frame is less likely to generate innovative responses. This paper shows that ethical mechanisms such as an extended concept of responsibility and moral legitimacy actually increase the likelihood of perceiving opportunities, rather than threats, and hence react innovatively to emerging competitive challenges.

The fourth paper [I Do Not Want to Be Green: Prosocial Motivation Effects on Firm Environmental Innovation Rejection Decisions, by Bari L. Bendell] extends the analysis to look at the interplay between focal decision makers (business owners) and their customers. The paper shows that prosocial motivation per se does not lead to the adoption of greener practices, despite the presence of wellknown technological options. This paper, on the basis of original, primary data focused on the US dry cleaning industry, shows that business owners have to respond to multiple demands from their customer base. Given this fragmentation and multiplicity of demands, the main driver behind the adoption of environmental innovation becomes high customer compatibility, rather than pro-social motivation per se. This paper raises the issue of the interplay between focal decision makers and the stakeholders with which they interact. Such interactions may play a rather conservative role in innovation decisions, lacking any explicit coordination mechanism.

This latter point is picked by the fifth paper [Innovation in Multistakeholder Setting: The Case of a Wicked Issue in Health Care, by Ruehli, Sachs and Schmitt]. In this paper, the discussion focuses on how participative stakeholder innovation can be leveraged to overcome major design problems, characterized by the presence of multiple, inconsistent objectives, in terms of both social needs and technological bottlenecks. On the basis of a detailed case study of the Swiss Cardiovascular Network, the authors put forward an evaluation framework whose task is that of revealing and aligning objectives, preferences, resources and decision-making criteria of all the relevant stakeholders in order to identify tensions and conflicts as the relevant technological and organizational design decisions are being taken (as opposed to wait for a design to be frozen, when it is too late to introduce major changes).

The last paper also focuses on tensions arising from conflicting objectives. This paper [Stakeholders Matter: How Social Enterprises Address Mission Drift, by Tommaso Ramus and Antonino Vaccaro], addresses an issue that received scant attention in the social innovation literature, i.e. mission drift. Relying on a comparative case study analysis, it explores strategies that can address mission drift in social enterprises. Results show that a combination of stakeholder engagement with social accounting can successfully support the rebalancing effort of a hybrid organization experiencing mission drift. On the contrary, strategies mostly focused on social accounting only, a quite typical approach in current times, are unsuccessful because they fail to boost the process necessary to re-introduce and operationalize in day-to-day life pro-social values and objectives.

This symposium is the result of a 3-year collaborative research project between IESE Business School and the Chair of Technology and Innovation Management of ETH Zurich. The papers here included were presented and discussed during the conference "Ethics, technology an organizational innovation" hosted in January 2014 by ETH in Zurich.

There are many people we would like to thank for their great contribution to this event. Among others we would like to remember: Michele Andreaus, Barbara La Cara, Luca Savettiere, Eliana Amato, Christine Ecker and Rosario Magre Miro.

\section{References}

Adolphson, D. (2004). A new perspective on ethics, and economics. Journal of Business Ethics, 54(3), 201-213.

Battilana, J., \& Lee, M. (2014). Advancing research on hybrid organizing-Insights from the study of social enterprises. Academy of Management Annals, 8(1), 397-441.

Berrone, Pascual, Fosfuri, Andrea, Gelabert, Liliana, \& GomezMejia, Luis R. (2013). Necessity as the mother of 'green' inventions: Institutional pressures and environmental innovations. Strategic Management Journal, 34(8), 891-909.

Floridi, L. (2009). Information ethics: A very short introduction. Oxford: Oxford University Press.

Gino, F. \& Staats, B. (2012). Samasource: Give work not aid! HBS Case study, 9-912-011.

Kaplan, D. (2004). Readings in the philosophy of technology. Lanham: Rowman and Littlefield.

Madsen, P. (2005). Responsible design and the management of ethics. DMI Review, 16(3), 37-41.

Santos, F. (2012). A positive theory of social entrepreneurship. Journal of Business Ethics, 111(3), 335-351.

Scherer, A. G., \& Palazzo, G. (2007). Toward a political conception of corporate social responsibility: Business and society seen 
from a habermasian perspective. Academy of Management Review, 32(4), 1096-1120.

Scherer, A. G., \& Palazzo, G. (2011). The new political role of business in a globalized world: A review of a new perspective on CSR and its implications for the firm, governance, and democracy. Journal of Management Studies, 48(4), 899-931.

Tatton-Brown, M. 2012. Facebook private message scandal prompts privacy questions, Wired, 25 September 2012, http://www.wired. co.uk/news/archive/2012-09/25/facebook-private-message-hack.
Thomke, S. (2003). Experimentation matters: Unlocking the potential of new technologies for innovation. Boston: Harvard Business School Press.

Vaccaro, A. (2012). To Pay or not to Pay? Dynamic transparency and the fight against the Mafia's extortionists. Journal of Business Ethics, 106(1), 23-35.

Vaccaro, A., \& Madsen, P. (2009). Transparency: The new ICTdriven Ethics? Ethics and Information Technology, 11(2), 113-122. 